\title{
Effect of atorvastatin on oxidative stress parameters and lipid profile in type 2 diabetic patients
}

\author{
Najah $\mathrm{RH}^{\mathrm{a}}$, Mohammad $\mathrm{AAH}^{\mathrm{b}}$ and Ammar RMR \\ aDept. of Pharmacology, Kufa Faculty of Medicine, Kufa, IRAQ \\ 'Dept. of Medicine,Kufa Faculty of Medicine, Kufa ,IRAQ
}

\begin{abstract}
Introduction: Evidence has long existed regarding the relationship between oxidative stress and diabetes. The present study was conducted to assess the effect of atorvastatin on selected oxidative stress parameters in the form of reduced glutathione (GSH), lipid peroxidation byproduct malondialdehyde (MDA) levels, glutathione -S- transferase (GST) activity and catalase (CAT) activity) and its effect on lipid profile (total cholesterol (TC), triglyceride (TG), high density lipoprotein $(H D L)$, low density lipoprotein (LDL) and very low density lipoprotein (VLDL) in dyslipidaemic type 2 diabetic patients. Materials and Methods: Fifty nine dyslipidaemic type 2 diabetic patients were included in this study. Full history was taken and general examination of patients was performed. Patients studied were taking glibenclamide (an oral hypoglycaemic drug) during the study as a treatment for their disease. These patients were followed up for 60 days and divided randomly into 2 groups. Group I $(n=31)$ : no drug was given and served as dyslipidaemic diabetic control. Group II $(n=28)$ : received atorvastatin tablets $20 \mathrm{mg}$ once daily at night. Of the 59 Fifty patients, $46 \mathrm{com}$ pleted the study while 13 patients withdrew. This is due to non compliance of the patients. Blood samples were drawn from the patients at the beginning and after 60 days of follow up between 8:30 \& 10:30 am after at least 12-14 hours fast. Fasting blood glucose, lipid profile, selected oxidative stress parameters (GSH, MDA levels, GST and CAT activities) were measured. Renal and hepatic functions were also assessed. Results: This study revealed that: atorvastatin treatment increased serum GSH; reduced MDA levels significantly while did not significantly affect CAT and GST activity. In atorvastatin treatment, TC, TG, LDL and VLDL decreased significantly while HDL increased significantly. Conclusion: There was insignificant correlations between atorvastatin induced changes in the oxidation markers and the observed changes of the lipid profile.
\end{abstract}

KEYWORDS; Atorvastatin, Type 2 Diabetes, Oxidative Stress

\section{INTRODUCTION}

Oxidative stress is defined as tissue injury resulting from a disturbance in the equilibrium between the production of reactive oxygen species (ROS) also known as free radicals and antioxidant defense mechanisms. 1 Under physiologic conditions, the antioxidant defenses are able to protect against the deleterious effects of ROS, but under conditions where an increase in oxidant generation, a decrease in antioxidant protection or a failure to repair oxidative damage, accumulation of free radicals ensues, leading to cellular and tissue damage.2 ROS are any molecular species capable of independent existence that contain one or more unpaired electrons in an atomic orbital. 3 They include molecules like hydrogen peroxide, ions like hypochlorite ion, and radicals like hydroxyl radical and superoxide anion which is both ion and radical.4 Excess generation of ROS in oxida-

Correspondence author

Prof. Dr. Najah R. Hadi

Head Dept. of Pharmacology,

Po Box 18, Kufa Faculty of Medicine,

Kufa, IRAQ

E-Mail:drnajahhadi@yahoo.com tive stress have pathological consequences including damage to polyunsaturated fatty acids in membrane lipids, proteins, DNA and ultimately cell death. 5 ROS have been implicated in many disease state including neurodegenerative disease like Alzheimer,s and Parkinson,s disease, atherosclerosis, inflammatory conditions, certain cancers, diabetes mellitus (DM), cataract in the eye, pulmonary, renal, heart diseases and the process of aging.6,7 Diabetes mellitus is a group of metabolic disorders with one common manifestation: hyperglycaemia associated with defects in insulin secretion, action or both. Traditionally it has been classified into two forms Type 1 DM and Type 2 DM.8 Type 2 DM which is known to be multifactorial, resulting from combination of various factors such as impaired fatty acid metabolism, central fat deposition leading to insulin resistance in various tissues (liver, muscles, adipose), beta-cell secretary defect and obesity.6,9 Evidence has long existed regarding the relationship between oxidative stress and DM.10 Eisei $\mathrm{N}$. et al postulated that oxidative stress is involved in the onset and progression of diabetes, initiation and exacerbation of micro- and macrovascular complications in diabetes and recently oxidative stress status markers have been associated directly with the severity and prognosis of diabetes.11 There are multiple sources of oxidative stress in DM, including 
non enzymatic (glucose autoxidation, non enzymatic glycation of proteins), enzymatic (NADPH oxidase, nitric oxide synthase) and mitochondrial pathway.12 Dyslipidaemia is used to describe a group of conditions in which there are abnormal levels of lipid and lipoprotein in the blood.13 In type 2 diabetes, dyslipidaemia is characterized by elevated circulating levels of TG, decreased circulating levels of HDL and usually accompanied by an elevation of small dense LDLcholesterol particles.14 There is evidence indicating that hyperlipidaemia is associated with enhanced oxidative stress.15 Atorvastatin belongs to 3-hydroxy3-methylglutaryl-coenzyme A (HMG-CoA) reductase inhibitors, or statins which are potent inhibitors of cholesterol biosynthesis that are used extensively to treat patients with hypercholesterolaemia.16,17

Atorvastatin is a synthetic lipid lowering agent.18 It is a competitive inhibitor of HMG-CoA reductase which catalyzes the conversion of HMG-CoA to mevalonate, an early rate limiting step in cholesterol biosynthesis resulting in depletion the intracellular supply of cholesterol.19 Inhibition of cholesterol biosynthesis is accompanied by an increase in hepatic LDL receptor on the cell surface which promotes uptake and clearance of circulating LDL. Thus the end result is a reduction in plasma cholesterol both by lowered cholesterol synthesis and by increased catabolism of LDL.17 Atorvastatin also reduce VLDL-C, TG and produce variable increase in HDL-C.20 Atorvastatin is safe and generally well tolerated.21 Mild gastrointestinal side effects like dyspepsia, flatulence, abdominal pain, diarrhea and constipation .Others headache, rash, pruritus and malaise. The most detrimental adverse effect of atorvastatin is hepatotoxicity and myopathy. 22 Munford RS. \& Shishehbor MH. et al stated that the overall clinical benefits observed with atorvastatin therapy appear to be greater than what might be expected from changes in lipid levels alone, suggesting effects beyond cholesterol lowering called pleiotropic effects.23,24 Vishal T. et al indicated that some of the cholesterol-independent effects of atorvastatin involve improving endothelial function, enhancing the stability of atherosclerotic plaques, decreasing oxidative stress, decreasing inflammation, improving insulin resistance, inhibiting the thrombogenic response in the vascular wall and impeding tumor cells. Furthermore statin have other extrahepatic beneficial effects on the immune system, central nervous system and bone.25 Atorvastatin possesses antioxidant properties by reducing lipid peroxidation and ROS production.25 Atorvastatin reduces the susceptibility of lipoproteins to oxidation both in vitro and in vivo i.e. they decrease the LDL oxidation. 25 Sugiyama $M$. et al investigated the effect of atorvastatin in patients with hyperlipidaemia and they concluded that atorvastatin has beneficial effects on oxidative stress and the lipid profile in those patients. The extra-lipid effects are not attributable to the lipid lowering effect of statin suggesting that the pleiotrpic effects of atorvastatin are independent of its effects on the lipid profile.26 Aguilar-Salinas CA. et al confirmed that atorvastatin exert marked efficacy and safety in improving the lipid profile in hyperlipidaemic type 2 diabetic patients. 27

The Aim of This Study was to clarify the effect of atorvastatin on selected oxidative stress parameters namely (reduced glutathione (GSH), lipid peroxidation product MDA levels, glutathione -S- transferase (GST) and catalase (CAT) activities) and lipid profile in dyslipidaemic type 2 diabetic patients.

\section{MATERIALS \& METHODS}

Fifty nine patients (age : $57.16 \pm 1.34$ years ; 32 men and 27 women) with type 2 DM (mean fasting blood glucose $7.91 \pm 0.7 \mathrm{mmol} / \mathrm{l}$, with a mean duration of diabetes of $8.4 \pm 1.08$ years) and dyslipidaemia (mean LDL-C level $5.48 \pm 0.72 \mathrm{mmol} / \mathrm{l}$ ) attending Al- Hakeem center for research and treatment of DM in Al-Sadr Teaching Hospital in Najaf City in the period between 5 th Nov. 2006 to 24 th June 2007 were included in this study. These patients underwent full history and complete physical examination. Patients with the following criteria were excluded from the study:

1- $\quad$ Patients who used any vitamin preparation or statins in the last three months. 28

2- $\quad$ Patients with renal insufficiency, defined as a serum creatinine level equal to or more than $1.8 \mathrm{mg} / \mathrm{dl} .24$

3- $\quad$ Patients with liver disease. 24

4- Hypertensive patients, because this condition affects oxidative stress. 15 In addition to this, antihypertensive drugs may affect lipid profile and oxidative stress in hy pertensive patients.29,30

5- Patients with chronic inflammatory diseases. 28

6- $\quad$ Alcoholics and smokers were also excluded. 31

Those patients were taking glibenclamide (Glibesyn . Medochemie LTD-Cyprus, Glibils. Hikma-Jordon) (an oral hypoglycaemic agent) during the study as a treatment for their disease that is diabetes. According to the design of the study, type 2 diabetic patients were followed up for 60 days and divided randomly into two groups:

1- $\quad$ Group I $(n=31)$ : No drug was given and served as dyslipidaemic diabetic control.

2- 2- Group II $(\mathrm{n}=28)$ : Received atorvastatin tablets $20 \mathrm{mg}$ once daily at night (Atorfit-20. Ajanta Pharma Limited. India. Batch no. AM0086F).

From those 59 patients included in this study, forty six patients reached the end of the study while 13 patients withdrew ( 8 patients from Group I and 5 patients from Group II). This is due to non compliance of the patients. The patients were put on diet control and followed every 2 weeks during the time of the study in order to ensure that they were using the medication properly, to supply the drug to the patients and to regularly check fasting blood glucose. Values of fasting blood glucose before, during and af- 
ter the study were controlled within the previously mentioned range; they were comparable between the groups. Blood samples were drawn from the patients at the beginning and after 60 days of follow up between 8:30 and 10:30 am after at least 12-14 hours of fasting. Fasting blood glucose, lipid profile, selected oxidative stress parameters (GSH, MDA levels, GST, CAT activities) were measured. Renal and hepatic functions were also assessed.

Serum GSH assay: Serum GSH was estimated accord- ing to a modified method utilizing Ellman reagent (DTNB). 32 The used reagents were supplied by Biochemicals Co. Ltd for EDTA and GSH, Sigma Co. Ltd for DTNB. The assay mixture contained serum and DTNB 0.01 (5, 5'-dithiobis-(2-nitrobenzoic acid), trichloroacetic acid (TCA $50 \%$ ), tris-EDTA buffer (0.2 M) PH 8.9, EDTA Na2 (0.2M) and GSH standards for preparation of stock standard solution and standard calibration curve in $\mu M$ (Figure 1). the net results read at $412 \mathrm{~nm}$ by using (Shimadzu UV-visible 1650PC) spectrophotometer.

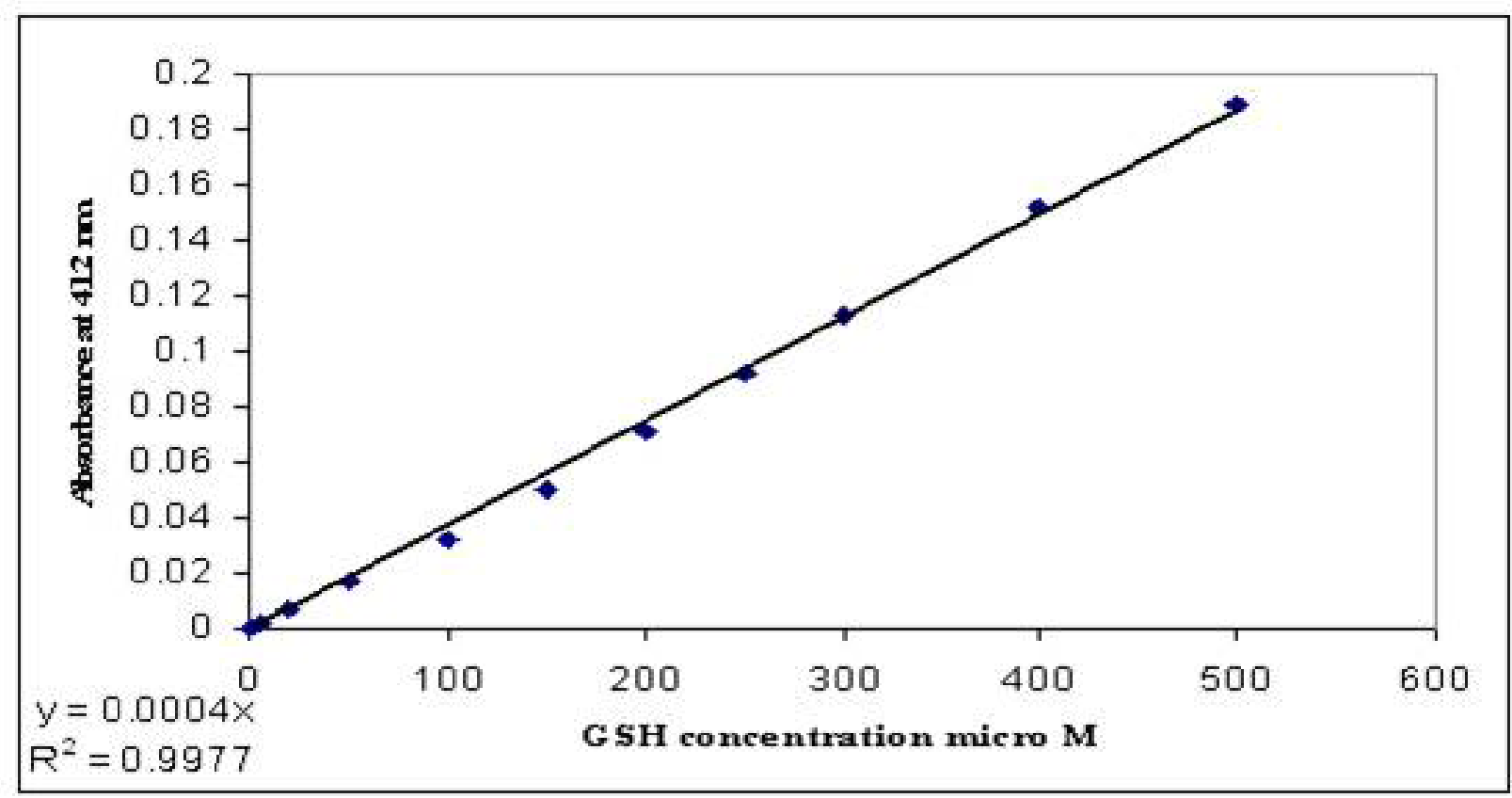

Figure 1. Standard curve for GSH determination

Serum MDA assay: The level of serum MDA was determined by a modified procedure described by (Guidet B. and Shah SV.). 33 All the chemicals were supplied by Merck Co. Ltd. The assay mixture contained serum and $17.5 \%$ TCA, $70 \%$ TCA, $0.6 \%$ thiobarbituric acid (TBA) and (Shimadzu UV-visible 1650PC) spectrophotometer used to read the final sample at $532 \mathrm{~nm}$. The concentration of MDA was expressed in molar.

Serum GST enzyme activity assay: Serum GST activity determined by Habig WH. et al method. 34 The used reagents were supplied by Analar grade for CDNB, K2HPO4 and KH2PO4. Biochemicals Co. Ltd for GSH. The assay mixture contained serum, GSH, 1-chloro, 2, 4-dinitrobenzene (CDNB), phosphate buffer ( $\mathrm{PH}$ 6.25) and (Shimadzu UV-visible 1650PC) spectrophotometer used to read the final sample at $340 \mathrm{~nm}$.

Serum catalase activity assay: Serum catalase activity determined by Aebi H. method. 35 The used reagents were supplied by Analar grade for Na2HPO4, $\mathrm{KH} 2 \mathrm{PO} 4$ and $\mathrm{H} 2 \mathrm{O} 2$. The assay mixture contained diluted serum, phosphate buffer, hydrogen peroxide (30 $\mathrm{mM}$ ) and (Shimadzu UV-visible 1650PC) spectrophotometer used to read the final sample at $240 \mathrm{~nm}$.

Serum lipid profile assay: Total cholesterol, triglyceride, high density lipoprotein were measured according to procedures supplied by BioMerieux Company using Shimadzu UV-visible 1650PC spectrophotometer.
Serum LDL \& VLDL measured according to the Friedewald equation (36): $\mathrm{VLDL}=\mathrm{TG} / 2.2 . \mathrm{LDL}=\mathrm{TC}-$ HDL - VLDL.

Statistical methods: Data was expressed as mean \pm SEM unless otherwise stated . Statistical analyses were done by using paired t-test. Pearson,s correlations were also performed with significant difference was set at $\mathrm{P}<0.05$.

\section{RESULTS}

Effect of atorvastatin on oxidative stress parameters: Atorvastatin treatment increased serum GSH, reduced MDA level significantly while did not significantly affect serum GST \& CAT activity. Oxidative stress parameters insignificantly changed in diabetic control group apart from significant increase in MDA level (Table I). 
Table 1. Effect of atorvastatin (20 mg / day) on oxidative stress parameters after 60 days of treatment and changes in dyslipidaemic diabetic control ( $n=23$ in each group).

\begin{tabular}{|c|c|c|c|c|c|c|}
\hline \multirow[b]{2}{*}{ Parameters } & \multicolumn{3}{|c|}{ Diabetic control } & \multicolumn{3}{|c|}{ Atorvastatin } \\
\hline & $\begin{array}{l}\text { Before } \\
\text { treatment }\end{array}$ & $\begin{array}{c}\text { After } \\
\text { treatment }\end{array}$ & Pvalue & $\begin{array}{l}\text { Before } \\
\text { treatment }\end{array}$ & $\begin{array}{c}\text { After } \\
\text { treatment }\end{array}$ & P value \\
\hline $\begin{array}{c}\text { GSH } \\
(\mathrm{mmol} / \mathrm{l})\end{array}$ & $0.24 \pm 0.0079$ & $0.22 \pm 0.0036$ & $>0.05$ & $0.23 \pm 0.0034$ & $0.40 \pm 0.0009$ & $<0.01$ \\
\hline MDA & $1.25 \times 10^{-4}$ & $1.59 \times 10^{-4}$ & $<0.01$ & $1.24 \times 10^{-4}$ & $0.24 \times 10^{-4}$ & $<0.01$ \\
\hline$(\mathrm{mol} / \mathrm{l})$ & \pm 0.0146 & \pm 0.0210 & & \pm 0.0178 & \pm 0.004 & \\
\hline $\begin{array}{l}\text { GST } \\
(\mathrm{U} / \mathrm{l})\end{array}$ & $13.68 \pm 0.18$ & $13.87 \pm 0.2194$ & $>0.05$ & $13.95 \pm 0.234$ & $14.07 \pm 0.212$ & $>0.05$ \\
\hline $\begin{array}{c}\text { CAT } \\
(\mathrm{K} / \mathrm{ml})\end{array}$ & $0.49 \pm 0.0123$ & $0.5001 \pm 0.016$ & $>0.05$ & $0.48 \pm 0.0133$ & $0.483 \pm 0.012$ & $>0.05$ \\
\hline
\end{tabular}

Effect of atorvastatin on lipid profile: Atorvastatin treatment decreased serum level of TC, TG, LDL and VLDL significantly while significantly increased HDL level. Lipid profile did not significantly change in diabetic control group (Table 2).

Table 2. Effect of atorvastatin (20 mg / day) on lipid profile after 60 days of treatment and changes in dyslipidaemic diabetic control ( $\mathrm{n}=23$ in each group).

\begin{tabular}{|cccc} 
Parameters & $\begin{array}{c}\text { Biabetic control } \\
\text { Before }\end{array}$ After treatment Pvalue & $\begin{array}{c}\text { Before } \\
\text { treatment }\end{array}$ & Atorvastatin \\
After treatment & Pvalue
\end{tabular}

$\begin{array}{ccccccc}\begin{array}{c}\text { TC } \\ (\mathrm{mmol} / \mathrm{l})\end{array} & 6.99 \pm 0.1173 & 6.74 \pm 0.0332 & >0.05 & 7.49 \pm 0.0230 & 4.38 \pm 0.0189 & <0.01 \\ \begin{array}{c}\mathrm{TG} \\ (\mathrm{mmol} / \mathrm{l})\end{array} & 2.78 \pm 0.0645 & 2.68 \pm 0.0159 & >0.05 & 2.84 \pm 0.0145 & 1.78 \pm 0.0069 & <0.01 \\ \begin{array}{c}\mathrm{HDL} \\ (\mathrm{mmol} / \mathrm{l})\end{array} & 0.81 \pm 0.0300 & 0.76 \pm 0.0114 & >0.05 & 0.76 \pm 0.0159 & 1.06 \pm 0.0109 & <0.01 \\ \begin{array}{c}\mathrm{LDL} \\ (\mathrm{mmol} / \mathrm{l})\end{array} & 4.90 \pm 0.1300 & 4.75 \pm 0.0339 & >0.05 & 5.43 \pm 0.0243 & 2.51 \pm 0.0168 & <0.01 \\ \begin{array}{c}\mathrm{VLDL} \\ (\mathrm{mmol} / \mathrm{l})\end{array} & 1.26 \pm 0.0129 & 1.21 \pm 0.0031 & >0.05 & 1.29 \pm 0.0029 & 0.81 \pm 0.0013 & <0.01 \\ & & \text { Values expressed as mean } \pm \mathrm{SEM} . & & \end{array}$

Correlations between observed changes in oxidation markers and observed changes in lipid parameters in atorvastatin group: There were no significant correlations between atorvastatin induced changes in the oxidation markers and the observed changes in the lipid profile (Table III).
Table 3. Pearson, s correlation for changes in the oxidative markers and lipid parameters in the atorvastatin group.

$\begin{array}{lcccc} & \text { GSH } & \text { MDA } & \text { GST } & \text { CAT } \\ \text { TC } & -0.232 & 0.042 & 0.43 & -0.119 \\ \text { TG } & -0.172 & -0.11 & 0.04 & -0.135 \\ \text { HDL-C } & -0.223 & -0.07 & 0.22 & -0.139 \\ \text { LDL-C } & -0.083 & 0.088 & 0.33 & -0.032 \\ \text { VLDL-C } & -0.157 & 0.001 & -0 & -0.055\end{array}$




\section{DISCUSSION}

Effect on oxidative stress parameters: Serum GSH level increased significantly following atorvastatin treatment and this finding was in agreement with that reported by Save V. et al.37 Also atorvastatin showed a significant reduction in the MDA level that is the same result reached by Koter $M$. et al.38 The increment of GSH and reduction of MDA by atorvastatin in our study was attributed to the antioxidant mediated effect of atorvastatin which result from inhibition of mevalonate pathway leading to the reduction in the synthesis of important intermediates including isoprenoids (farnesyl pyrophosphate \& geranylgeranyl pyrophosphate) which serve as lipid attachments for intracellular signaling molecules in particular inhibition of small GTPase binding proteins (Rho, Rac, Ras and $G$ proteins) whose proper membrane localization and function are dependent on isoprenylation. These proteins modulate a variety of cellular processes including signaling, differentiation and proliferation.39,40 Atorvastatin attenuates endothelial ROS formation through attenuating endothelial superoxide anion production by inhibition of NAD (P) H oxidase activity via Rho dependent mechanism. Some of antioxidant effects of atorvastatin may be due to its metabolites such as hydroxyl metabolites which have direct antioxidant effect. Atorvastatin improves and preserves the level of vitamin C, E and endogenous antioxidant such as reduced glutathione. 18 The protective effects of atorvastatin on reactive oxygen species (ROS) including cholesterol dependent and non cholesterol dependent antioxidative properties 18 . Serum GST enzyme activity did not significantly change in atorvastatin treatment and this finding was consistent with Passi S. et al who concluded that atorvastatin had no effect on GST activity.41 Our study demonstrated that atorvastatin showed no significant change in the CAT activity. This finding was in agreement with Passi $\mathrm{S}$. et al but Wassmann S. et al who concluded that atorvastatin caused a significant increase in the CAT activity. 41,42 This discrepancy was due to the fact that the sample size may be relatively small permitting chance observations to exert substantial effects.

Effect on lipid profile: Atorvastatin treatment decreased serum level of TC,TG, LDL and VLDL significantly while increased serum HDL significantly and this finding was in agreement with that obtained by Diabetes Atorvastatin Lipid Intervention study group and Save V. et al.37,41 The mechanism involved was largely attributed to the ability of atorvastatin to impair cholesterol synthesis via inhibiting the enzyme HMG-CoA reductase which is the rate limiting step in cholesterol biosynthesis. This both decreases circulating lipoproteins and increases their uptake by up regulating hepatic LDL-C receptors. The overall lipid lowering effect include increase uptake and degradation of LDL-C, inhibition of LDL-C oxidation, reduction in cholesterol accumulation and esterification and decreases lipoprotein secretion and cholesterol synthesis.44,24
According to this study there were insignificant correlations between the observed changes in the pleiotropic effect of atorvastatin regarding antioxidant properties and the improvement in the lipid profile, that is the same finding reached by Sakabe K. et al.45 This pleiotropic effect of atorvastatin is due predominantly to inhibition of isopreniods but not cholesterol synthesis. 46

From the results of this study, we can conclude that, atorvastatin increased GSH; reduced MDA levels and had no effect on CAT and GST activities. Atorvastatin reduced TC, TG, LDL-C, VLDL-C and increased HDL-C levels. Also there were no correlations between the observed changes in the oxidation markers and the improvement of the lipid profile in the atorvastatin.

\section{REFERENCES}

1. Betteridge DJ. What is oxidative stress? Metabolism 2000; 49:3-8

2. Halliwell B. Free radicals, antioxidants and human disease: Curiosity, cause or consequence. Lancet 1994; 344:721-4

3. Mercure F, Quagliaro L, Ceriello A. Oxidative stress evaluation in Diabetes. Diabetes Technol Ther 2000; 2:4

4. Maytin M, Leopold J, Loscalzo J. Oxidant stress in the vasculature. Curr Atheroscler Rep 1999; 1:146-6

5. Kannan K, Jain SK. Oxidative stress and apoptosis. Pathophysiology 2000; 7:153-63

6. Shah S, Iqbal M, Karam J, Salifu M, Mcfarlane SI. Oxidative stress, glucose metabolism and the prevention of type 2 diabetes: pathophyi ological insights. Antioxid Redox Signal 2007; 9:911-29

7. Young IS, Woodside JV. Antioxidants in health and disease. J Clin Pathol 2001; 54:176-86

8. Florence JA, Yeager BF. Treatment of type 2 diabetes mellitus. Am Fam Physician 1999; 59:10

9. Mehta JL, Rasouli N, Sinha AK, Molavi B. Oxidative stress in diabetes: A mechanistic overview of its effects on atherogenesis and myocardial dysfunction. Int J Biochem Cell Biol 2006; 38:794-803

10. Oberley LW. Free radicals and diabetes. Free Rad Bio Med 1988; 5:113-24

11. Eisei N, Hirokazu T. Parameters for measure ment of oxidative stress in diabetes mellitus: applicability of ELISA for clinical evaluation. J Investig Med 2005; 53:167-75

12. Johansen LS, Harris AK, Rychly D, Ergul A. Oxidative stress and the use of antioxidants in diabetes: linking basic science to clinical practice. Cardiovasc Diabetol 2005; 4:5

13. Patel J. Dyslipidaemia in diabetes. Clin Evid 2006; 15:555-75

14. Florkowski CM. Management of co-existing diabetes mellitus \& dyslipidaemia : defining the role of thiazolidinediones. Am J Cardio vasc Drugs 2002; 2:15-21 
15. Violi F, Loffredo L, Musella L, Marcoccia A. Should antioxidant status be considered in interventional trials with antioxidants? Heart 2004; 90:598-602

16. Sheffield MC. Multiple effects of statins in non lipid disease states. US Pharm 2004; 6:38-54

17. Liao JK. Isoprenoids as mediators of the biological effects of statins. J Clin Invest 2002; 110:285-8

18. Danesh FR, Kanwar YS. Modulatory effects of HMG-CoA reductase inhibitors in diabetic mi croangiopathy. FASEB J 2004; 18:805-15

19. Beltowski J. Statins and modulation of oxidative stress. Toxicol Mech Methods 2005; 15:61-92

20. Hodgson BB, Kizior RJ. Saunders nursing drug handbook. Philadelphia: Lippincott, 2003.

21. Heerey A, Barry M, Ryan M, Kelly A. The potential for drug interactions with statin therapy in Ireland. Indian J Med Sci 2001; 169:176-9

22. Ellsworth AJ, Witt DM, Dugdale DC, Oliver LM. Mosby's Medical Drug Reference.

St Louis: Mosby, 2006

23. Munford RS. Statins and the acute phase re sponse. N Engl J Med 2001; 344:2016-18

24. Shishehbor MH, Brennan ML, Aviles RJ, et al. Statins promotes potent systemic anti oxidant effects through specific inflammatory pathways. Circulation 2003; 108:426-31

25. Vishal T, Bano G, Khajuria V, Parihar A, GuptaS . Pleiotropic effects of statins. Indian J Pharmacol 2005; 37:77-85

26. Sugiyama M, Ohashi M, Takase H, Sato K, Ueda R, et al. Effects of atorvastatin on inflammation and oxidative stress. Heart Vessels 2005; 20:133-36

27. Aguilar-Salinas CA, Gomez-Perez FJ, Posadas-Romero C, et al. Efficacy and safety of atorvastatin in hyperlipidaemic type 2 diabetic patients. A 34-week multicenter open label study. Atherosclerosis 2000; 152:489-96

28. Marketou ME, Zacharis EA, Nikitovic D, et al. Early effects of simvastatin versus atorvastatin on oxidative stress and proinflammatory cytokines in hyperlipidaemic subjects. Angiology 2006; 57:211-18

29. Uzunova VV, Tolekova AN, llieva GS, Trifonova AP. Renin-angiotensin system and lipid peroxidation . Bulgaria J Vet Med 2005; 1:69-75

30. Kasiske BI, Ma JZ, Roberto SN, and Thomas AL. Effects of antihypertensive therapy on serum lipids. Ann Intern Med 1995;122:133-41
31. Kebapci N, Efe B, Akyuz F, Sunal E, Demirustu C. Oxidative stress and antioxidant therapy in type 2 diabetes mellitus. Turkish $\mathrm{J}$ Endocr Metabol 1999; 4:153-62

32. Ellman GL. Arch Biochem Biophys 1959; 82:70-7

33. Guidet B, Shah SV. Am J Physiol 1989; 257:440

34. Habig WH, Pabst MJ, Jakoby WB. Glutathione-S-transferase. The first enzymatic step in mercapturic acid formation. J Biol Chem 1974; 22:7130-9

35. Aebi H. Catalase. In: Bergmeyer HV ed. Methods in Enzymatic Analysis. New York: Academic Press 1974

36. Friedewald WT, Levy RI, Fredrickson DS. Estimation of the concentration of LDL-C in plasma without use the preparative ultracentrifuge. Clin Chem 1972; 18:499-502

37. Save V, Patil N, Moulik N, Rajadhyaksha G. Effect of atorvastatin on type 2 diabetic dyslipidaemia. J Cardiovasc Pharmacol Ther 2006; 11:262-70

38. Koter M, Broncel M, Chjnowska-Jezierska J, Klikczynska K, Franiak I. The effect of atorvastatin on erythrocyte membranes \& serum lipids in patients with type 2 hypercholesterolaemia. Eur J Clin Pharmacol 2002; 58:501-6

39. Liao JK, Laufs U. Pleiotropic effects of statins. Ann Rev Pharmacol Toxicol 2005; 45:89-118

40. Mason JC. Statins and their role in vascular protection. Clin Scien 2003; 105:251-66

41. Passi S, Stancato A, Aleo E, Dmitrieva A, Littarru GP. Statins lower plasma and lymphocyte ubiquinol / ubiquinone without affecting other antioxidants and PUFA. Bio factors 2003; 18:113-24

42. Wassmann S, Laufs U, Muller K, et al. Cellular antioxidant effects of atorvastatin in vitro and in vivo. Arterioscler Thromb Vasc Biol 2002; 22:300-5

43. DALI Study Group. The effect of aggressive versus standard lipid lowering by atorvastatin on diabetic dyslipidaemia; the DALI study : a double blind randomized placebo controlled trial in patients with type 2 diabetes and diabetic dyslipidaemia . Diabetes Care 2001; 24:1335-41

44. Alegret M, Silvestre JS. Pleiotropic effects of statins and related pharmacological experimental approaches. Methods Find Exp Clin Pharmacol 2006; 28:627

45. Sakabe K, Fukuda N, Wakayama K,Nada T, Shinohara $\mathrm{H}$. Effects of atorvastatin therapy on the low - density lipoprotein subfraction, remnant-like particles cholesterol, and oxidized low-density lipoprotein within 2 weeks in hypercholesterolemic patients. Circulation 2003; 67:866-70 
46. Laufs U, Liao JK. Isoprenoid metabolism and the pleiotropic effects of statins.

Curr Atheroscler Rep 2003; 5:372-8

\section{ARABIC SUMMARY}

داهجإلا تارشؤم ىل ع نيتاتسافروت ثال إقاقع ريثأت

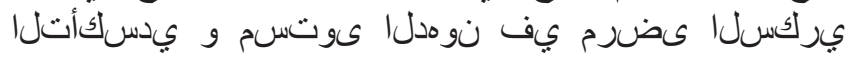

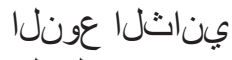

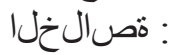

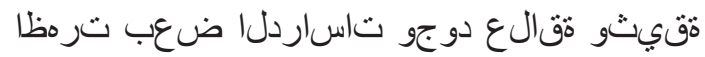

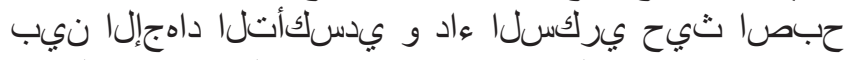

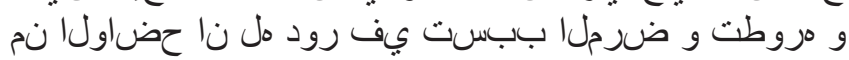

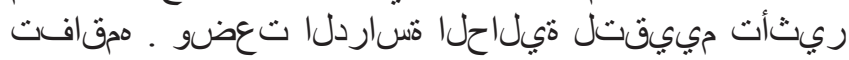

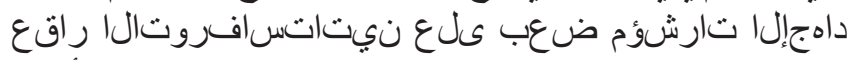

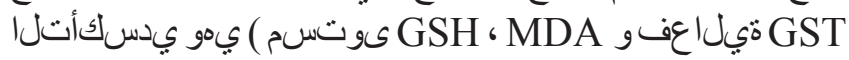

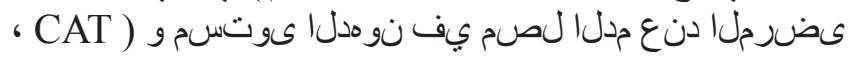

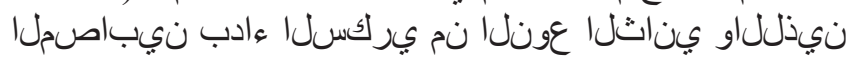

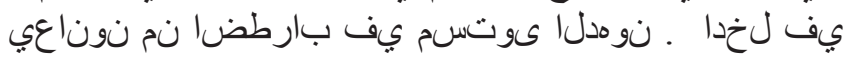

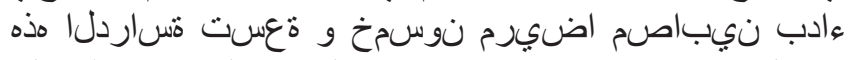

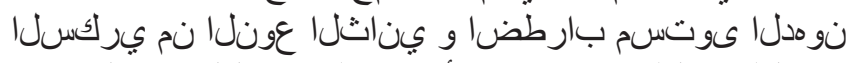

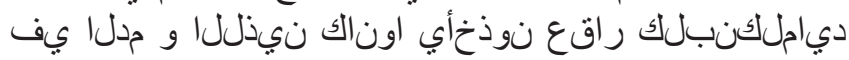

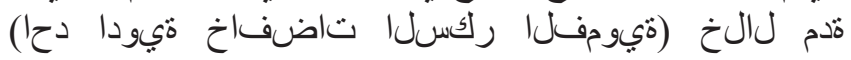

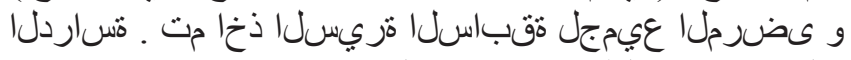

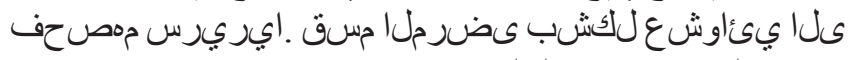

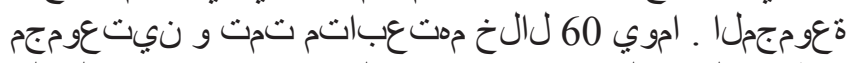

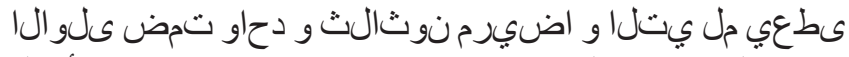

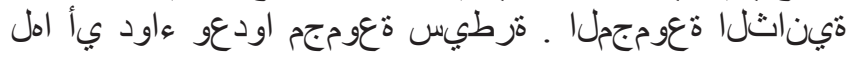

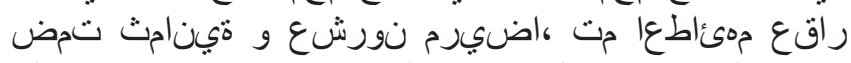

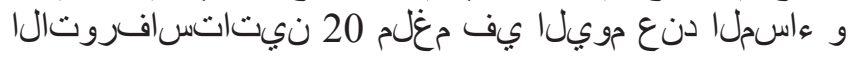

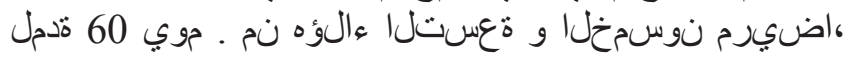

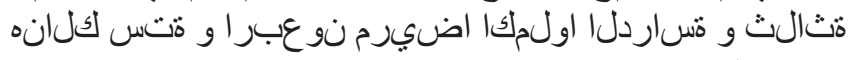

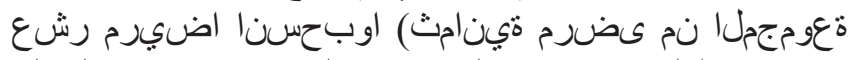

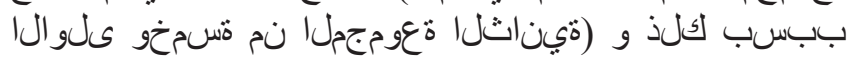

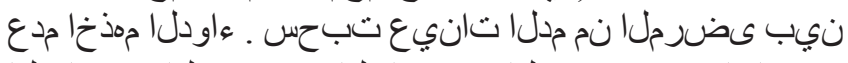

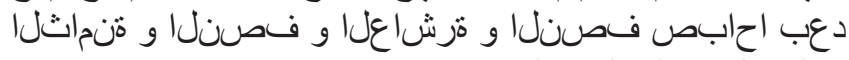

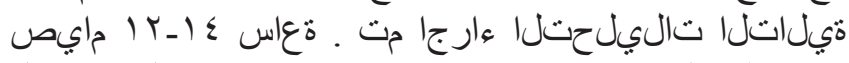

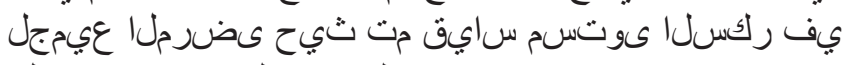

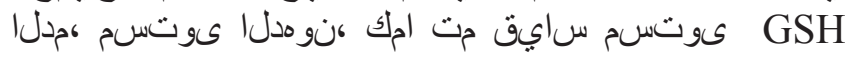

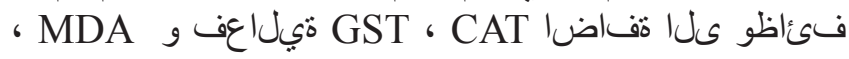

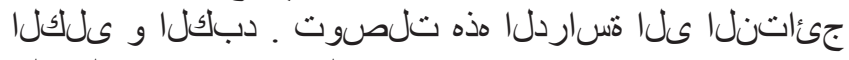

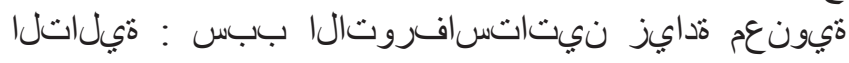

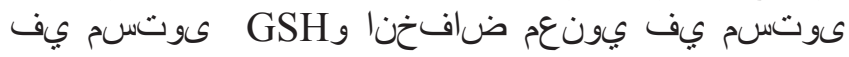
MDA تيل CAT و GST

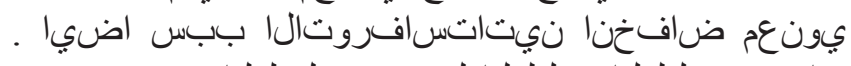

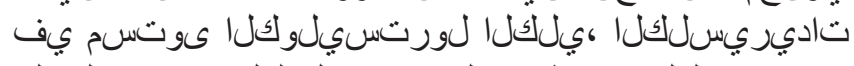

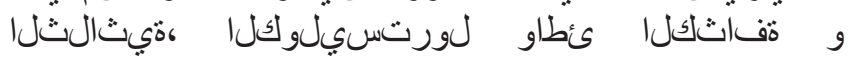

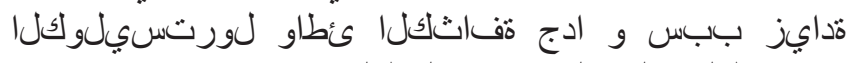

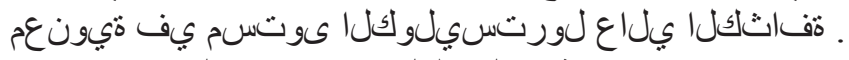

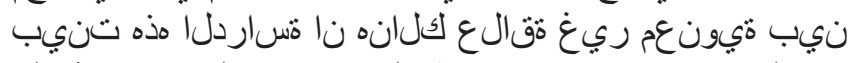

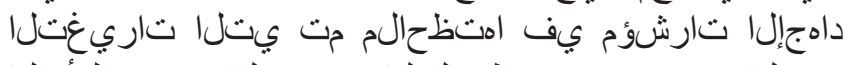

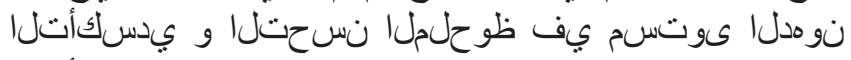

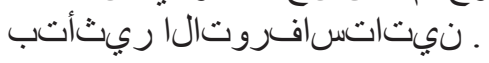


